\section{CARDIOLOGY}

Cardiology 1998;90:312
Received: June 22, 1998 Accepted: July 23, 1998

\section{Tsung O. Cheng}

Division of Cardiology, George Washington University, Washington D.C., USA

\title{
Seasonal Incidence of Acute Myocardial Infarction in the Chinese Population
}

Dear Sir

I read with interest the article by Ku et al. [1] from Taiwan. It was a surprise to me, however, to note that the authors found no seasonal variations in acute myocardial infarction in contradiction to many reports in the literature which the authors listed in their table 3. But the authors failed to cite one very important reference which appeared in the Chinese Journal of Internal Medicine [2]. The latter article was in Chinese and therefore should be familiar to $\mathrm{Ku}$ et al. who are also Chinese.

The authors of the article in the Chinese Journal of Internal Medicine were from the Guangzhou Municipal Cardiovascular Cooperative Group [2]. They analyzed 943 patients with acute myocardial infarction admitted between 1976 and 1980 to 18 hospitals in Guangzhou, which is better known to

Tsung O. Cheng, MD

Division of Cardiology, George Washington University 2150 Pennsylvania Ave. N.W.

Washington, DC 20037 (USA)

Tel. +1 (202) 994-4150, Fax +1 (202) 994-3673 the outside world as Canton [3]. They found the peak incidence to be in the winter months - January, February, April and October - and the lowest incidence in August when there was more frequent typhoon landing. Using regression analysis, they also found the incidence of acute myocardial infarction to increase under low humidity. Their findings were of special importance, because like the subjects in the article by $\mathrm{Ku}$ et al. [1] the subjects described in the article in the Chinese Journal of Internal Medicine [2] were also Chinese. Furthermore, Guangzhou lies exactly in the same latitude as Kaohsiung, Taiwan, where Ku et al. enrolled their patients.

That there is a definite meteorological influence on the incidence of acute myocardial infarction seems to be a universal phenomenon. For example, Ruhenstroth-Bauer et al. [4], from Germany, found a significant positive correlation between the onset of acute myocardial infarction and $28 \mathrm{kHz}$ atmospherics. Clearly there is more to the meteorological parameters than just the ambient temperature.

\section{References}

1 Ku C-S, Yang C-Y, Lee W-J, Chiang H-T, Liu C-P, Lin S-L: Absence of a seasonal variation in myocardial infarction onset in a region without temperature extremes. Cardiology 1998;89: $277-282$.

2 Guangzhou Municipal Cardiovascular Cooperative Group: A preliminary analysis on the relationship of the incidence of acute myocardial infarction to the meteorological factors in Guangzhou city. Chin J Intern Med 1984;23: 548-550.

3 Cheng TO: Myocardial infarction and the weather: A significant positive correlation between the onset of heart infarct and $28 \mathrm{KHz}$ atmospherics - a pilot study. Clin Cardiol 1985;8:510.

4 Ruhenstroth-Bauer G, Baumer H, Burkel EM, Sonning W, Filipiak B: Myocardial infarction and the weather: A significant positive correlation between the onset of heart infarct and 28 $\mathrm{KHz}$ atmospherics - a pilot study. Clin Cardiol 1985;8:149-151.
Dr. Chang-Sheng Ku and Dr. Shoa-Lin Lin Intensive Care Unit

802 Army General Hospital and

Veterans General Hospital-Kaohsiung

386, Dar-Chung 1st Road

Koahsiung City, Taiwan (ROC)

\section{Author's Reply}

The observation described in Chin $\mathrm{J}$ Int Med 1984;23:548-550 found that the peak incidence of acute myocardial infarction (AMI) was in winter months which, is consistent with a number of previous investigations (see the References section of our paper). We agree that the precipitating factors of AMI attacks are multifactorial; humidity is a crucial one as well.

Although Canton province (a southern province of mainland China) lies almost in the same latitude as Kaohsiung City, these two places may still not have the same weather. Unlike the Canton province, Taiwan is an island, it is neither very hot in summer nor very cold in winter. It never snows in Kaohsiung City in winter. Its climate is regulated by the Pacific Ocean and Taiwan Strait from both sides of this island, respectively. It is thus not surprising that there may have been different findings between these 2 places regarding the seasonal variation in AMI.

\section{KARGER}

Fax + 41613061234 E-Mail karger@karger.ch www.karger.com (c) 1999 S. Karger AG, Basel

0008-6312/98/0904-0312\$17.50/0

Accessible online at:

http://BioMedNet.com/karger 